\title{
A three-dimensional tattoo: molluscum contagiosum
}

\author{
Vincenzo De Giorgi MD, Marta Grazzini MD, Torello Lotti MD
}

Previously published at www.cmaj.ca

$\mathrm{T}$ wenty days after getting a tattoo on his arm, a 30-year-old immunocompetent man de veloped peculiar lesions at the tattoo site. He presented to our dermatology clinic three months later with umbilicated, skin-coloured, papular lesions that were asymptomatic (Figure 1A). His physical examination was otherwise normal and he had no clinical history of sexually transmitted diseases.

Serology results for syphilis, hepatitis B and C, and HIV were negative. Biopsy results confirmed our clinical diagnosis of molluscum contagiosum, with keratinocytes containing characteristic eosinophilic inclusion bodies due to poxvirus infection (Figure 1B). We presume that the molluscum contagiosum virus was inoculated by a contaminated needle.

Molluscum contagiosum, a viral infection most commonly observed in children, produces umbilicated papules in the epidermis. It is observed with a higher frequency in tropical climates, and predisposing conditions include atopic dermatitis, Darier disease and immunodeficiencies. In adults, molluscum contagiosum is recognized as a sexually transmitted disease..$^{1.2}$ Common warts and condylomata acuminata are the most common differential diagnoses for multiple small lesions, especially if they occur in genital areas. ${ }^{3.4}$ In immunocompromised patients, deep fungal infections like cryptococcosis, penicilliosis, histoplasmosis and coccidiomycosis can be similar in presentation to the lesions of molluscum contagiosum. ${ }^{2}$

Although in many patients lesions resolve spontaneously, active interventions can be divided into three categories:

From the Department of Dermatology, University of Florence, Florence, Italy CMAJ 2010. DOI:10.1503/cmaj.091480 destructive (chemical and physical), immunomodulatory and antiviral. ${ }^{5}$ The destructive approach (curettage, cryotherapy and topical application of keratolytic agents) is the most commonly used. We treated our patient's lesions with multiple sessions of curettage, and we advised him to avoid skin-toskin contact and to avoid shared towels and sheets.

This article has been peer reviewed.

Competing interests: None declared.

\section{REFERENCES}

1. Tyring SK. Molluscum contagiosum: the importance of early diagnosis and treatment. Am J Obstet Gynecol 2003;189(Suppl):S12-6.

2. Brown J, Janniger C, Schwartz RA, et al. Childhood molluscum contagiosum. Int J Dermatol 2006;45:93-9.

3. Scheinfeld NS. Molluscum contagiosum. Skinmed 2008;7:89-92.

4. Stulberg DL, Hutchinson AG. Molluscum contagiosum and warts. Am Fam Physician 2003;67:1233-40.

5. Hanna D, Hatami A, Powell J, et al. A prospective randomized trial comparing the efficacy and adverse effects of four recognized treatments of molluscum contagiosum in children. Pediatr Dermatol 2006;23:574-9. 